\title{
Metformin Associates With Aggressive Features of Endometrial Cancer in Women With Type 2 Diabetes
}

\author{
ELINA URPILAINEN ${ }^{1}$, REETTA ARIMA $^{2}$, PEETER KARIHTALA $^{3}$, ULLA PUISTOLA $^{1}$ and ANNE AHTIKOSKI ${ }^{4}$ \\ ${ }^{1}$ Department of Obstetrics and Gynaecology, PEDEGO Research Unit, Medical Research Center Oulu, \\ Oulu University Hospital and University of Oulu, Oulu, Finland; \\ ${ }^{2}$ Department of Obstetrics and Gynaecology, Central Finland Central Hospital, Jyväskylä, Finland; \\ ${ }^{3}$ Department of Oncology, University of Helsinki and Helsinki University \\ Comprehensive Cancer Center, Helsinki, Finland; \\ ${ }^{4}$ Department of Pathology, Cancer and Translational Medicine Research Unit, \\ Oulu University Hospital and University of Oulu, Oulu, Finland
}

\begin{abstract}
Background/Aim: Preclinical studies on metformin use and endometrial cancer have been promising but epidemiological studies have reported variable results. This study aimed to assess if metformin use is associated with endometrial cancer aggressiveness and survival in women with type 2 diabetes (T2D). Patients and Methods: This retrospective hospital-based cohort consisted of women with $T 2 D$ who were treated for endometrial cancer at the Oulu University Hospital, Finland, between 2007 and 2014. Results: The sample size was 121 patients: 58 metformin users and 63 metformin non-users. Intriguingly, type 2 histology, deep myometrial invasion and the presence of lymphovascular invasion were more common in the metformin user group. However, metformin use showed no association with overall survival and progression-free survival. Conclusion: Metformin use was associated with poorer prognostic factors in endometrial cancer patients with T2D.
\end{abstract}

Endometrial cancer is the fifth most common cancer type in women worldwide (1). The age-standardised incidence of endometrial cancer is rising mostly due to lifestyle factors such as obesity (2). Type 2 diabetes (T2D) is the most rapidly increasing chronic disease globally, and has been estimated that more than 460 million adults have diabetes,

This article is freely accessible online.

Correspondence to: Elina Urpilainen, MD, Ph.D., Department of Obstetrics and Gynaecology, PEDEGO Research Unit, Medical Research Center Oulu, Oulu University Hospital and University of Oulu P.O. Box 23, FIN-90029 Oulu, Finland. Tel +35 883152011 , e-mail: elina.urpilainen@gmail.com

Key Words: Metformin, endometrial cancer, survival, type 2 diabetes, prognostic factors, antidiabetic medication. with more than $90 \%$ of them suffering from T2D (3). Although, T2D and endometrial cancer share some risk factors, diabetes itself seems to be an independent risk factor for endometrial cancer (4).

The majority of endometrial cancers are diagnosed at an early stage (5). Regarding early endometrial cancer, the five-year survival rate is $95 \%$ but decreases to as low as $16 \%$ in stage IV cancer (6). Endometrial cancers are traditionally classified as type 1 and type 2 cancers and type 1 endometrial cancers are more frequent and have a better prognosis than type 2 cancers (7). Type 2 endometrial cancers are poorly differentiated and are more commonly identified by their deep invasion into the myometrium, higher frequency in pelvic lymph node metastases and decreased sensitivity to progesterone (7).

Metformin is the main first-line therapy for T2D (8). In the treatment of hyperglycaemia, metformin reduces the hepatic glucose outlay, increases peripheral tissue sensitivity and stimulates glucagon-like peptide-1 secretion (9). Metformin is also weight neutral (9) and has favourable effects on cancer cells both directly and indirectly (10). It sensitises tissues to insulin, decreases hepatic gluconeogenesis and reduces circulating insulin levels, and these effects indirectly lead to both reduced tyrosine kinase activation and phosphatidylinositol-3-kinase signalling (10).

Metformin has shown multiple molecular mechanisms in endometrial cancer cells (11). In in vitro studies, metformin seems to inhibit the proliferation and invasion of both endometrioid and non-endometrioid endometrial cancer cells (12-14). Metformin activates AMP-activated protein kinase and this leads to inhibition of mammalian target of rapamycin (15). In addition, it induces apoptosis (15), inhibits oxidative phosphorylation at the mitochondrial level and inhibits epithelial-to-mesenchymal transition (11). Metformin has been shown to synergize with chemotherapy and progesterone treatment in endometrial cancer cells (11). In addition, a 
meta-analysis of previous epidemiological studies indicated that metformin users have a better overall survival (OS) rate and a decreased risk of endometrial cancer recurrence (16).

This retrospective study was aimed to explore whether metformin users diagnosed with endometrial cancer have a less aggressive cancer phenotype or better survival rate in a hospital-based cohort with comprehensive clinical data.

\section{Patients and Methods}

Patients. The data of the patients included in this study were obtained from Oulu University Hospital records. These records included information on the patients' age at the time of diagnosis, parity, antidiabetic medication (ADM) and body mass index (BMI). In addition, we obtained information on endometrial cancer such as stage, histology, myometrial invasion, lymphovascular invasion (LVI), oestrogen receptor (ER) status, residual tumour after the surgery, progression and death from hospital records. All endometrial cancer diagnoses were based on histology. Stages were rechecked and fitted to the current International Federation of Gynaecology and Obstetrics (FIGO) stage (17). Endometrial cancers were categorised as type 1 and type 2 cancers according to their histology, so that grade 1 and grade 2 endometrioid endometrial cancers ( $n=63$ and $n=27$, respectively) and mucinous $(n=1)$ cancers were labelled as type 1 cancers, whereas grade 3 endometrioid $(n=11)$, serous $(n=13)$, clear cell $(n=1)$, mixed high grade $(n=3)$, undifferentiated endometrial cancers $(n=1)$ and carcinosarcomas $(n=1)$ were classified as type 2 cancers.

Classification of patients to metformin users and non-users was based on the ADM being used at the time of endometrial cancer diagnosis. Patients were classified as metformin users if they had used metformin alone or combined with some other oral ADMs. On the other hand, the patients were categorised as metformin non-users if they used only other forms of oral ADMs, insulin (alone or combined with metformin and/or other oral ADMs) or did not use any ADM.

The follow-up of the patient began at the time the endometrial cancer surgery was done, except for patients who were not eligible for surgery $(n=14)$. In those cases, the start of the follow-up was the date of diagnosis from the endometrial sample. Follow-up ended at the time of death or closure of the follow-up period (7th August 2018). The median follow-up time was 65 months.

Statistical analysis. Statistical analysis was performed with IBM SPSS Statistics, version 25 (IBM Corporation, Armonk, NY, USA) and GraphPad Prism, version 8.0.2 (GraphPad Software, San Diego, CA, USA) software. Comparisons between two medication groups were evaluated using the two-sample $t$-test and Mann-Whitney $U$ test for continuous variables and Pearson chi-square and Fisher's exact test for categorical variables. FIGO stage was distributed into two categories - early or advanced. Early stage included FIGO stages I A and I B, while advanced stage included stages II, III and IV. Kaplan-Meier curves with the log-rank test were applied to the survival analysis. OS was calculated from the time of surgery or cancer diagnosis to the time of death. Progression-free survival (PFS) was calculated from the time of the surgery or cancer diagnosis to the date of radiological progression. Cox regression analysis was applied for multivariate analysis, where the traditionally most important prognostic factors - age, histology and the stage of endometrial cancer - were included along with metformin use in the model. In all statistical analyses, $p$-values $<0.05$ were considered statistically significant.

\section{Results}

Patient and tumour characteristics. There were 121 women with T2D diagnosed with endometrial cancer between 2007 and 2014 at Oulu University Hospital in Finland (Figure 1). The metformin user group had 58 women, of which 35 were using metformin alone, while 23 were using metformin combined with some other oral ADMs. The metformin nonuser group had 63 patients - of which 37 were insulin users, 8 were using some other oral ADMs and 18 were not using any ADMs.

The mean age for endometrial cancer diagnosis was 70.5 years among the metformin users and 71.2 years among the metformin non-users $(p=0.67)$ (Table I). The metformin nonusers were slightly more obese than the metformin users, as median BMI was 33.0 in the metformin users and 36.0 in the metformin non-users $(p=0.11)$. Parity and the presence of fatty liver were similar in both groups.

There were more adverse prognostic factors in the metformin user group (Table II). Intriguingly, type 2 histology $(p=0.018)$ and the presence of LVI $(p=0.04)$ and deep myometrial invasion $(p=0.035)$ were more common in the metformin user group (Table II). There was also a trend of more advanced-stage endometrial cancers in the metformin user group $(p=0.07)$. However, there were no statistically significant differences in tumour size $(p=0.61)$, peritoneal cytology $(p=0.98)$ and ER status $(p=0.33)$ between the medication groups. In addition, residual tumour after surgery $(p=0.12)$, the number of patients who received adjuvant treatment $(p=0.12)$ and the number of patients who were not eligible for operation $(p=0.123)$ did not show statistically significant differences between metformin users and non-users.

Overall survival. As expected, univariate analysis showed OS was worse in patients with type 2 endometrial cancers than in patients with type $1 \quad(p=0.0000018)$ (Figure 2). Similarly, OS was worse in patients with advanced-stage cancer $(p=0.000013)$, patients $\geq 65$ years of age $(p=0.006)$ and patients with deep myometrial invasion $(p=0.0000093)$. ER status $(p=0.79)$ and BMI $(p=0.82)$ showed no association with OS.

Univariate analysis of the whole cohort revealed that metformin use had no association with OS $(p=0.67)$. Furthermore, metformin use was not associated with OS when assessed separately in subgroups of type 1 histology $(p=0.19)$, type 2 histology $(p=0.21)$, superficial myometrial invasion $(p=0.27)$, deep myometrial invasion $(p=0.57)$, presence of LVI $(p=0.31)$, early-stage cancer $(p=0.33)$, 


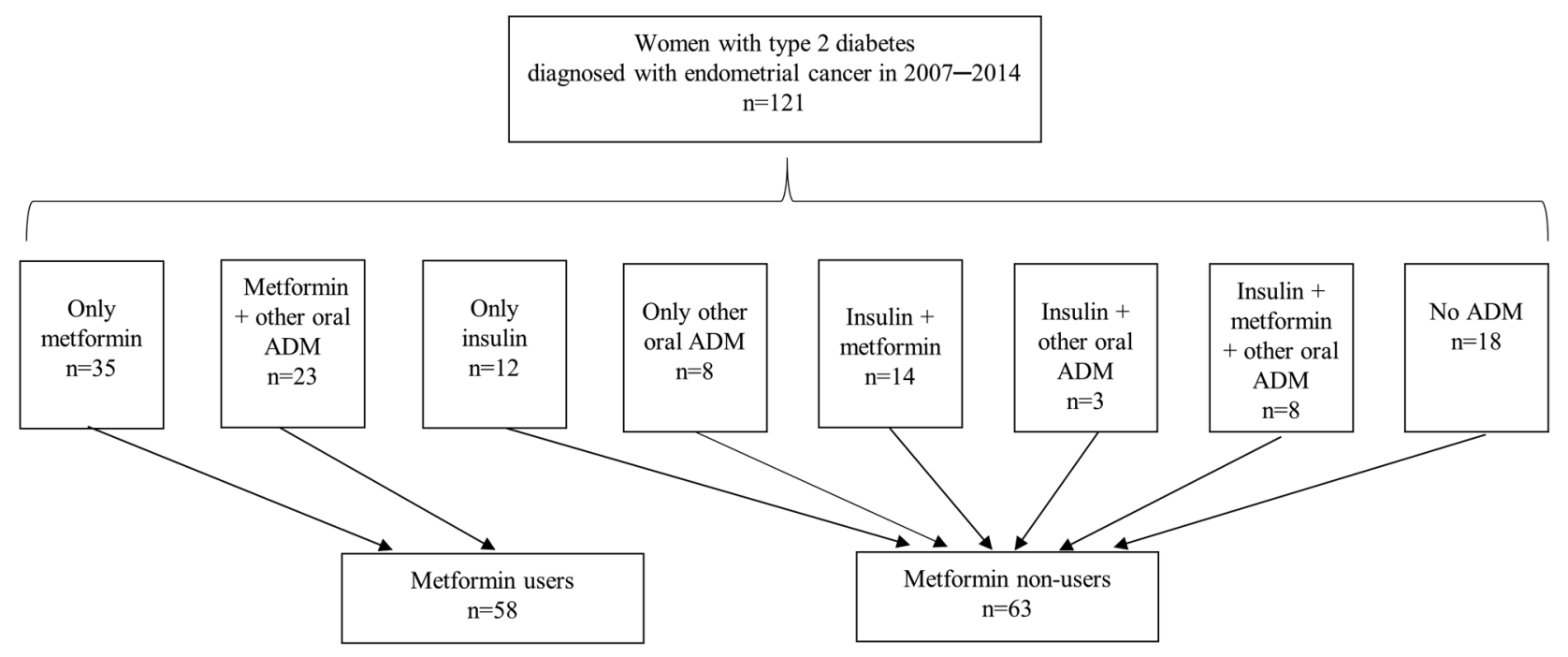

Figure 1. Distribution of antidiabetic medication (ADM).

advanced-stage cancer $(p=0.64)$, ER-negative endometrial cancers ( $p=0.87)$, ER-positive endometrial cancers $(p=0.57)$, higher BMI class $(p=0.22)$ and older patients $(p=0.35)$. Similarly, Cox regression analysis showed that metformin use was not associated with OS after adjusting for histology type, stage and patient's age [Hazard ratio $(\mathrm{HR})=0.86,95 \%$ confidence interval $(\mathrm{CI})=0.41-1.79]$ (Table III). In addition, advanced stage and type 2 histology were associated with poorer OS in the patients $\geq 65$ years old subgroup while advanced stage of cancer was only associated with poorer OS in the patients of type 2 histology subgroup.

Progression-free survival. Similar with OS, PFS was worse in type 2 histology $(p=0.000004)$, more advanced stage $(p=0.000000000001)$ and deep myometrial invasion $(p=0.0003)$ in univariate analysis (Figure 3$)$. However, older age $(p=0.11)$, higher BMI $(p=0.54)$ and ER negativity $(p=0.36)$ of the tumour showed no association with PFS.

In the whole cohort, metformin use was not associated with PFS $(p=0.1)$ in univariate analysis. However, metformin use was associated with poorer PFS in type 2 histology $(p=0.015)$. In addition, metformin use is associated with poorer PFS in older patients $(p=0.015)$. Nevertheless, metformin use was not linked with PFS when separately assessed in subgroups of type 1 histology $(p=0.2)$, superficial myometrial invasion $(p=0.18)$, deep myometrial invasion $(p=0.5)$, higher BMI class $(p=0.091)$, presence of LVI $(p=0.1)$, ER-positive cancer $(p=0.26)$, ER-negative cancer $(p=0.06)$, early-stage cancer $(p=0.44)$ or advanced-stage cancer $(p=0.51)$. However, in the Cox regression analysis, the advanced stage was the only factor that was associated with poorer PFS after adjusting for metformin use, histology and age (Table III). When Cox regression analysis was done only among patients with either type 2 histology or among those $\geq 65$ years age, in both of these analyses, only advanced stage was an adverse prognostic factor for PFS.

\section{Discussion}

Metformin has shown various anti-cancer effects on endometrial cancer cells in preclinical studies. In addition to its growth inhibitive effect (12), metformin seems to sensitise endometrial cancer cells to both chemotherapy (18) and progestins (19).

In a small clinical study, preoperative use of metformin was associated with lower cell proliferation, Ki-67 expression, in endometrial cancer (20). Contrary to this finding, a recent phase III study did not find reduced tumour proliferation in endometrial cancer among metformin users (21). Metformin has also been found to prevent tamoxifenassociated endometrial proliferative changes in breast cancer patients (22).

Thus, contrary to most previous results, in the current hospital-based cohort study, metformin use at the time of endometrial cancer diagnosis in women with T2D was found to be associated with poorer prognostic factors, but no associations with either OS or PFS were found. Although the majority of previous retrospective cohort studies have indicated that metformin use is associated with better survival in patients with endometrial cancer, this evidence is not robust. Few studies have observed a better OS among metformin users with endometrial cancer, including all histological endometrial cancer types $(23,24)$ while better OS was only noted in non-endometrioid subtype in one study 
Table I. Patient characteristics in the two medication groups: metformin users and non-users. STD: Standard deviation, BMI: body mass index, WPRT: whole-pelvic radiation therapy. Significant p-Value is given in bold.

\begin{tabular}{|c|c|c|c|}
\hline & $\begin{array}{c}\text { Metformin } \\
\text { users } \\
(\mathrm{n}=58)\end{array}$ & $\begin{array}{c}\text { Metformin } \\
\text { non-users } \\
(\mathrm{n}=63)\end{array}$ & $p$-Value \\
\hline \multicolumn{4}{|l|}{ Age at diagnosis (years) } \\
\hline Mean & 70.5 & 71.2 & \multirow[t]{4}{*}{0.667} \\
\hline STD & 8.56 & 9.36 & \\
\hline Min & 51 & 51 & \\
\hline $\operatorname{Max}$ & 88 & 88 & \\
\hline \multicolumn{4}{|l|}{ Age group at diagnosis } \\
\hline$<65$ years & 19 & 14 & \multirow[t]{2}{*}{0.194} \\
\hline$\geq 65$ years & 39 & 49 & \\
\hline \multicolumn{4}{|l|}{ BMI $\left(\mathrm{kg} / \mathrm{m}^{2}\right)$} \\
\hline Median & 33.0 & 36.0 & \multirow[t]{3}{*}{0.106} \\
\hline Range & $19-55$ & $22-65$ & \\
\hline Missing & 4 & 6 & \\
\hline \multicolumn{4}{|l|}{ BMI class $\left(\mathrm{kg} / \mathrm{m}^{2}\right)$} \\
\hline$<35$ & 34 & 21 & \multirow[t]{3}{*}{0.008} \\
\hline$\geq 35$ & 21 & 36 & \\
\hline Missing & 4 & 6 & \\
\hline \multicolumn{4}{|l|}{ Menopause age } \\
\hline Premenopausal & 2 & 3 & \multirow[t]{5}{*}{0.479} \\
\hline Under age 50 & 6 & 9 & \\
\hline $50-53$ years old & 24 & 26 & \\
\hline$\geq 54$ years old & 18 & 11 & \\
\hline Missing & 8 & 14 & \\
\hline \multicolumn{4}{|l|}{ Fatty liver } \\
\hline Yes & 21 & 21 & \multirow{3}{*}{0.315} \\
\hline No & 16 & 25 & \\
\hline Missing & 21 & 17 & \\
\hline \multicolumn{4}{|l|}{ Parity } \\
\hline Median & 2 & 2 & \multirow[t]{2}{*}{0.317} \\
\hline Range & $0-9$ & $0-13$ & \\
\hline \multicolumn{4}{|l|}{ Adjuvant treatment } \\
\hline None & 27 & 31 & \multirow[t]{6}{*}{0.307} \\
\hline WPRT & 11 & 11 & \\
\hline Chemotherapy & 13 & 6 & \\
\hline Vaginal brachytherapy & 4 & 8 & \\
\hline Intracavitary radiation & 2 & 6 & \\
\hline Hormonal treatment & 1 & 1 & \\
\hline
\end{tabular}

(25). In contrast to this, a lower risk for recurrence has been reported in type 1 endometrioid cancers in metformin users in another study (26).

On the other hand, similar to our study, some studies have not observed any association between metformin use and survival in patients with endometrial cancer (27-29). In our previous register-based studies, metformin use was not associated with lower endometrial cancer-related mortality in either endometrioid or non-endometrioid histologies, but metformin users had lower mortality from other causes among endometrioid endometrial cancer patients $(30,31)$.
Table II. Tumour characteristics in the two medication groups: metformin users and non-users. ER: Oestrogen receptor. Significant pValues are given in bold.

\begin{tabular}{|c|c|c|c|}
\hline & $\begin{array}{c}\text { Metformin } \\
\text { users } \\
(\mathrm{n}=58)\end{array}$ & $\begin{array}{c}\text { Metformin } \\
\text { non-users } \\
\quad(\mathrm{n}=63)\end{array}$ & $p$-Value \\
\hline \multicolumn{4}{|l|}{ Histology } \\
\hline Type 1 & 38 & 53 & \multirow[t]{2}{*}{0.018} \\
\hline Type 2 & 20 & 10 & \\
\hline \multicolumn{4}{|l|}{ Stage } \\
\hline Early (IA-IB) & 37 & 47 & \multirow[t]{3}{*}{0.07} \\
\hline Advanced ( $\geq \mathrm{II})$ & 19 & 11 & \\
\hline Missing & 2 & 5 & \\
\hline \multicolumn{4}{|c|}{ Deep myometrial invasion } \\
\hline Yes & 26 & 15 & \multirow[t]{3}{*}{0.035} \\
\hline No & 28 & 38 & \\
\hline Missing & 4 & 10 & \\
\hline \multicolumn{4}{|c|}{ Lymphovascular invasion } \\
\hline Yes & 24 & 12 & \multirow[t]{3}{*}{0.04} \\
\hline No & 31 & 37 & \\
\hline Missing & 3 & 14 & \\
\hline \multicolumn{4}{|l|}{ ER status } \\
\hline Positive & 49 & 51 & \multirow[t]{3}{*}{0.33} \\
\hline Negative & 7 & 12 & \\
\hline Missing & 2 & 0 & \\
\hline \multicolumn{4}{|l|}{ Peritoneal cytology } \\
\hline I-II & 41 & 42 & \multirow[t]{5}{*}{0.976} \\
\hline III & 2 & 2 & \\
\hline IV & 3 & 2 & \\
\hline $\mathrm{V}$ & 2 & 2 & \\
\hline Missing & 10 & 15 & \\
\hline \multicolumn{4}{|c|}{ Residual tumour after surgery } \\
\hline No & 49 & 52 & \multirow[t]{4}{*}{0.118} \\
\hline Yes & 4 & 0 & \\
\hline No operation & 4 & 10 & \\
\hline Missing & 1 & 1 & \\
\hline
\end{tabular}

In a previous meta-analysis, no association between metformin use and endometrial cancer risk was seen (16); however, histological subtypes were not analysed separately. No association between metformin use and nonendometrioid endometrial cancer incidence was seen in our previous study (31), rather, metformin ever-use was linked with increased risk for endometrioid endometrial cancer among the patients compared to those who had never used metformin (32).

In our present study, metformin use was associated with poorer prognostic factors, which may interfere with the survival results. The most established negative prognostic factors for endometrial cancer, advanced-stage cancer and type 2 histology were also the most important factors impacting on survival in our study, suggesting that the cohort was representative. However, analysing histological subtypes separately is not reliable due to the small amount of type 2 cancers, particularly the non-endometroid type $(n=30)$. In 
(a)

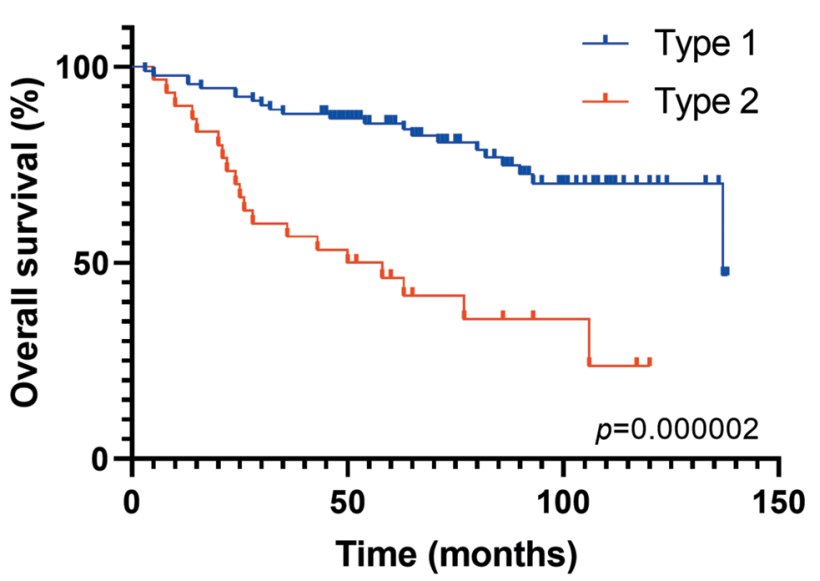

(c)

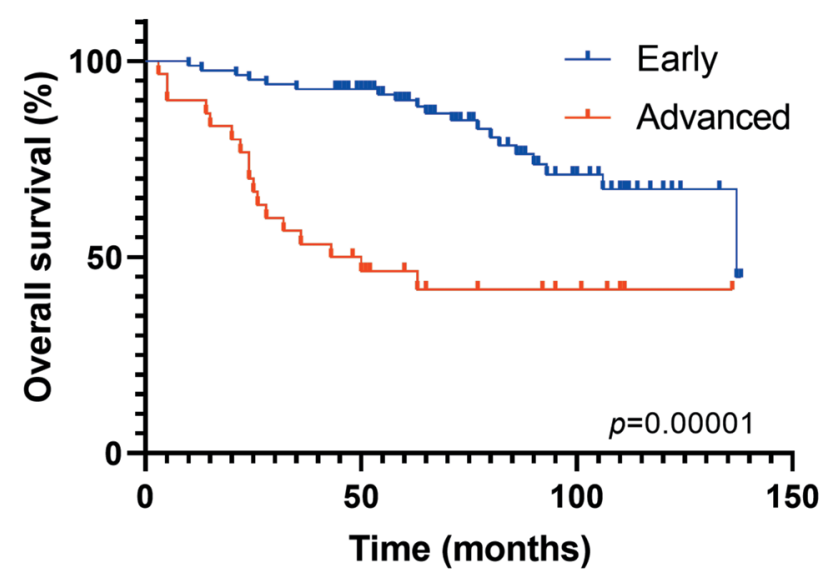

(b) Deep myometrial invasion

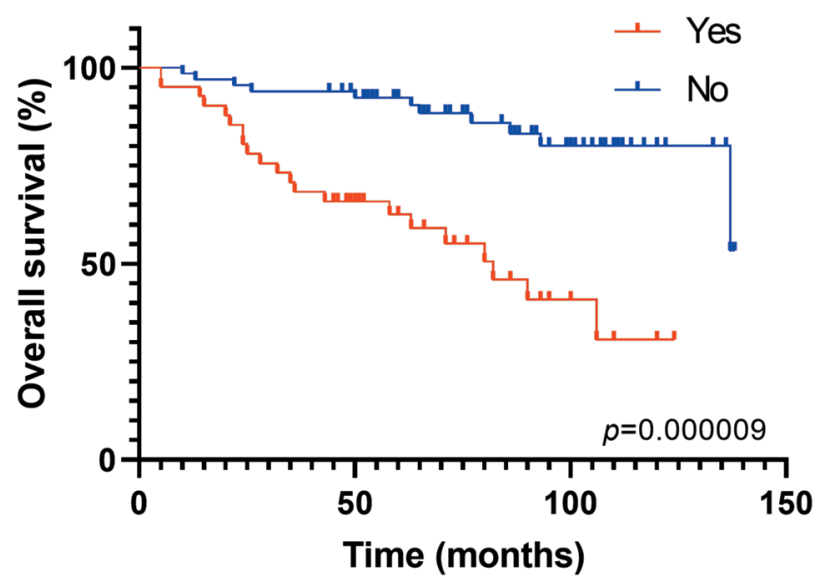

(d)

Metformin use

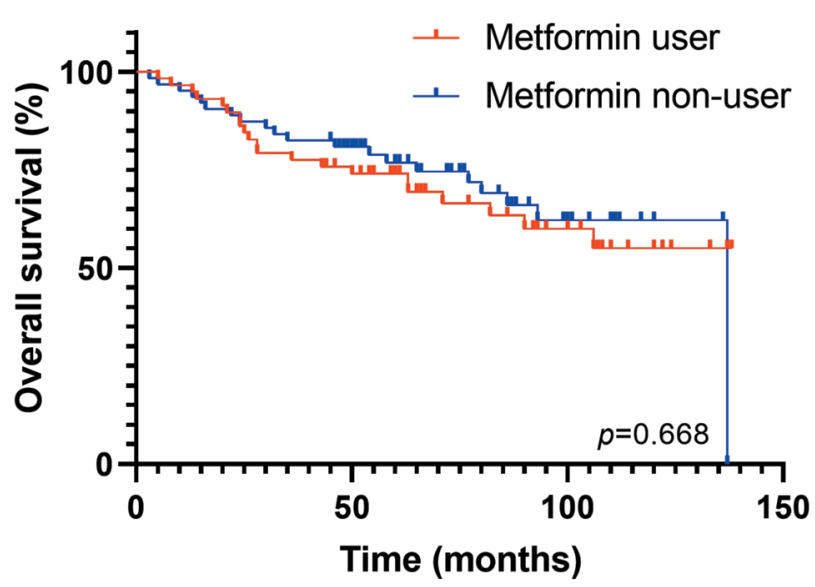

Figure 2. Kaplan-Meier curves demonstrate associations between (a) histology, (b) myometrial invasion (c) stage or (d) metformin use and overall survival.

previous studies, metformin use was not linked to more aggressive histology or more advanced stage (23-26, 28, 29). However, similar to our study, metformin users were younger in some of the previous studies $(24,30)$, while others have not reported such a difference $(23,25,26)$. In some studies, metformin users had higher BMI than metformin non-users, which is in contrast to our findings $(26,28,29)$. Also, a better OS in metformin users with higher BMI has been reported (28).

The strengths of this study include reliable data on patient and cancer characteristics, and, over five-year median follow up. We had the patients' data at the time of endometrial diagnosis, such as BMI and parity, and cancer-related data such as ER status and myometrial invasion, which are usually missing in register-based studies. On the other hand, as a limitation, information on the cause of death was not available and the sample size was not very extensive due to the single-institution based records. The information on duration and severity of diabetes and dose of the used medications were lacking, which might lead to bias, as longer duration of diabetes is associated with, for example, increased cardiovascular mortality (33). We presumed continuous ADM exposure after the endometrial cancer operation, though we could not verify the duration of medication use through prescription data.

We observed heterogeneity among the medication groups, as multiple medication use is common in patients with T2D, which is consistent with the previous retrospective clinical studies. The metformin non-user group included 22 patients who also used insulin alongside metformin. Although the 
(a)
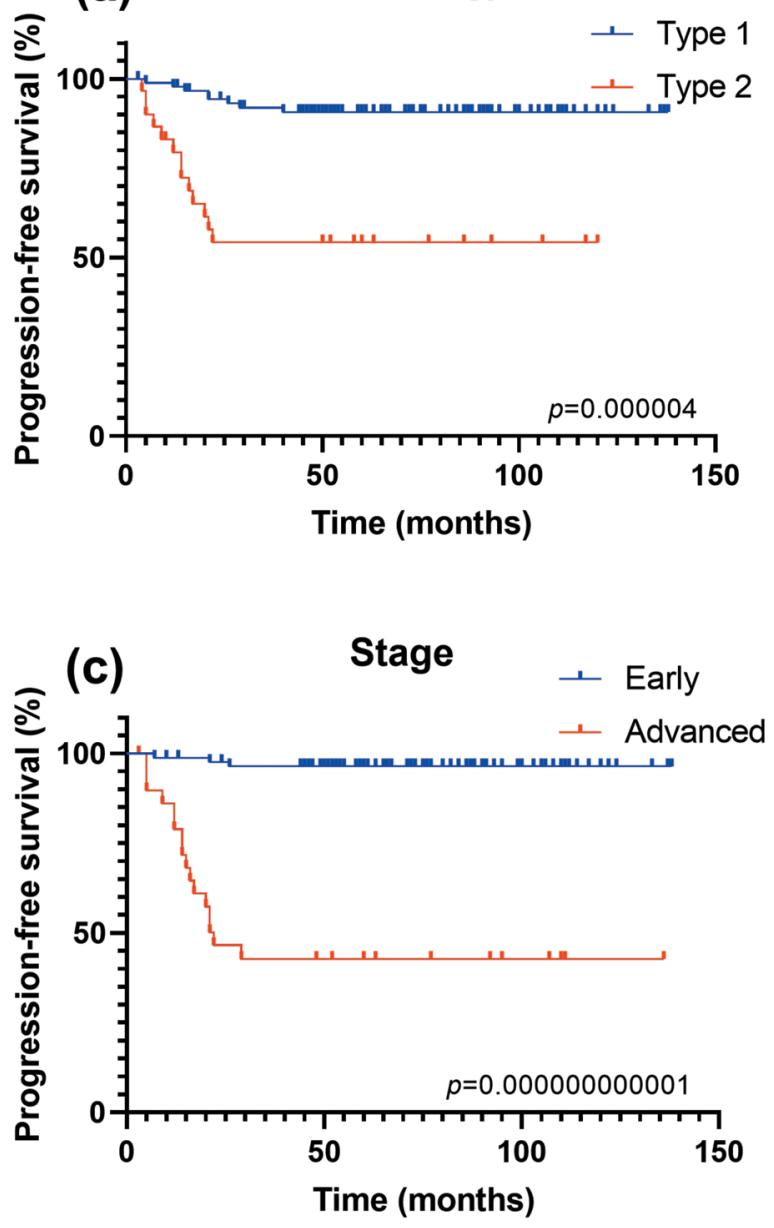

(b) Deep myometrial invasion

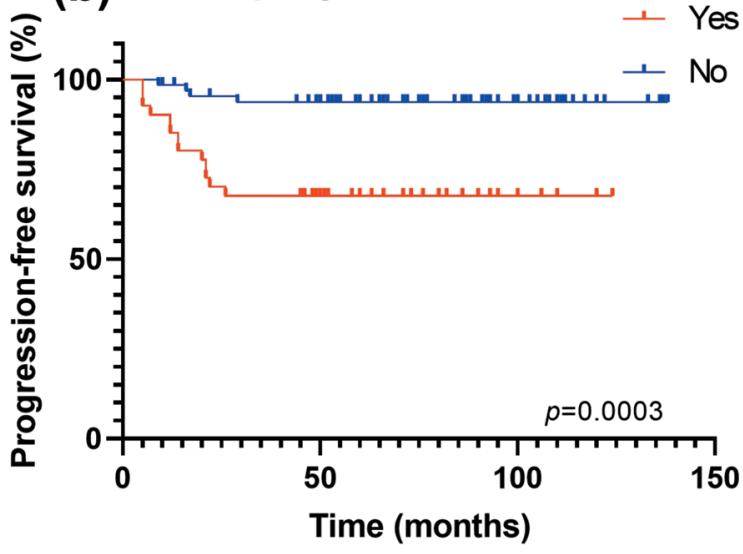

Metformin use

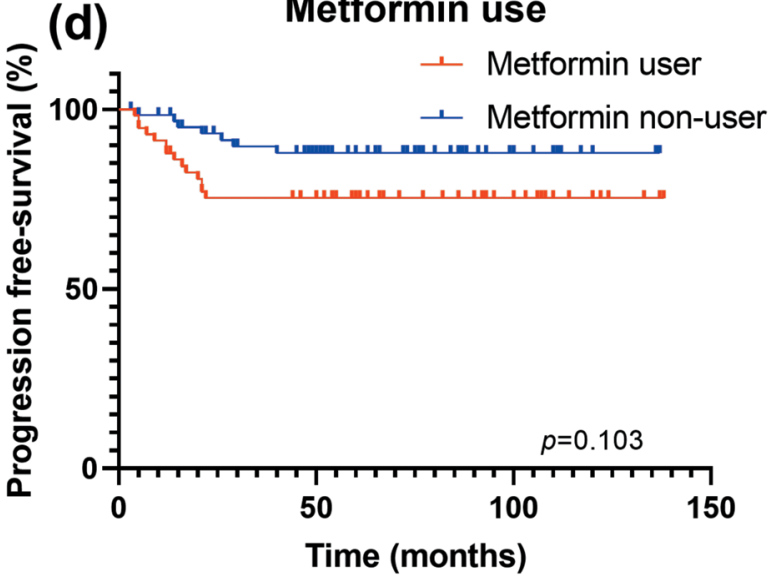

Figure 3. Kaplan-Meier curves demonstrate associations between (a) histology, (b) myometrial invasion (c) stage or (d) metformin use and progression-free survival.

Table III. The results of multivariate analysis. Significant p-Values are given in bold.

\begin{tabular}{|c|c|c|c|c|c|c|}
\hline & \multicolumn{3}{|c|}{ Overall survival } & \multicolumn{3}{|c|}{ Progression-free survival } \\
\hline & Hazard ratio & $95 \%$ Confidence interval & $p$-Value & Hazard ratio & $95 \%$ Confidence interval & $p$-Value \\
\hline Stage & 2.279 & $1.038-5.006$ & 0.04 & 16.001 & $4.225-60.602$ & 0.00004 \\
\hline Histology & 3.516 & $1.688-7.322$ & 0.001 & 2.357 & $0.734-7.566$ & 0.15 \\
\hline Age at diagnosis & 1.058 & $1.012-1.106$ & 0.013 & 0.996 & $0.937-1.057$ & 0.886 \\
\hline Metformin use & 0.858 & $0.411-1.794$ & 0.685 & 1.081 & $0.357-3.266$ & 0.891 \\
\hline
\end{tabular}

majority of previous epidemiological studies have classified patients as metformin ever-users or metformin never-users, we decided to categorise those patients who used metformin along with insulin into the metformin non-user group. In a Danish study, insulin initiation was a stronger predictor of death from other causes in many types of cancer itself (34). Also, in one of our previous studies, insulin use was associated with increased mortality from other causes than endometrial cancer (30). Furthermore, mortality from cancer is increased in patients who use metformin or sulphonylureas with 
subsequent insulin treatment compared with patients not using insulin (35). Insulin is not only an important regulator of cell metabolism but also a growth factor for cancer cells in vitro via its receptor and insulin-like-growth factor 1 receptor (36).

The current knowledge and data from the Cancer Genome Atlas (TCGA) define four clinically distinct endometrial cancer types based on their p53 mutational burden, exonuclease domain of the DNA polymerase epsilon (POLE) mutations and microsatellite instability $(37,38)$. We were unable to recategorize our endometrial cancer cases according to TCGA. Lack of information on p53 mutation status in our study is probably a minor limitation since most grade 3 endometrioid carcinomas with p53 mutation would anyway have a poor prognosis and belong to the type 2 cancer group. POLE mutation analysis is not yet available in every-day cancer diagnostics, so these rare cancers with p53 mutation but better prognosis are not currently identified. Microsatellite instability (MSI) status was not analysed in the primary diagnostics in our patient group.

\section{Conflicts of Interest}

The Authors have no conflicts of interest to declare regarding this study.

\section{Authors' Contributions}

EU and RA collected the data; AA revised the histological cancer data/properties; EU performed statistical analysis and wrote the original draft of the manuscript; EU, RA, PK, UP, and AA revised subsequent drafts and approved the final draft for submission. All Authors have read and agreed to the published version of the manuscript.

\section{Acknowledgements}

This study was funded by grants from the Jane and Aatos Erkko Foundation (T59127) and the Finnish Government Research Funds (K77729) granted to the University Hospital of Oulu. The funders had no role in the design of the study; in the collection, analyses, or interpretation of data; in the writing of the manuscript, or in the decision to publish the results.

\section{References}

1 Ferlay J, Colombet M, Soerjomataram I, Mathers C, Parkin DM, Piñeros M, Znaor A and Bray F: Estimating the global cancer incidence and mortality in 2018: GLOBOCAN sources and methods. Int J Cancer 144(8): 1941-1953, 2019. PMID: 30350310. DOI: $10.1002 /$ ijc. 31937

2 Raglan O, Kalliala I, Markozannes G, Cividini S, Gunter MJ, Nautiyal J, Gabra H, Paraskevaidis E, Martin-Hirsch P, Tsilidis KK and Kyrgiou M: Risk factors for endometrial cancer: An umbrella review of the literature. Int J Cancer 145(7): 17191730, 2019. PMID: 30387875. DOI: 10.1002/ijc.31961

3 IDF Diabetes Atlas, 2019. Available at https://diabetesatlas.org/ [Last accessed on 1st August 2020]
4 Liao C, Zhang D, Mungo C, Tompkins DA and Zeidan AM: Is diabetes mellitus associated with increased incidence and disease-specific mortality in endometrial cancer? A systematic review and meta-analysis of cohort studies. Gynecol Oncol 135(1): 163-171, 2014. PMID: 25072931. DOI: 10.1016/ j.ygyno.2014.07.095

5 Morice P, Leary A, Creutzberg C, Abu-Rustum N and Darai E: Endometrial cancer. Lancet 387(10023): 1094-1108, 2016. PMID: 26354523. DOI: 10.1016/S0140-6736(15)00130-0

6 Siegel RL, Miller KD and Jemal A: Cancer statistics, 2019. CA A Cancer J Clin 69(1): 7-34, 2019. PMID: 30620402. DOI: 10.3322/caac. 21551

7 Bokhman JV: Two pathogenetic types of endometrial carcinoma. Gynecol Oncol 15(1): 10-17, 1983. PMID: 6822361. DOI: 10.1016/0090-8258(83)90111-7

8 Flory J and Lipska K: Metformin in 2019. JAMA 321(19):19261927, 2019. PMID: 31009043. DOI: 10.1001/jama.2019.3805

9 Chatterjee S, Khunti K and Davies MJ: Type 2 diabetes. Lancet 389(10085): 2239-2251, 2017. PMID: 28190580. DOI: 10.1016/S0140-6736(17)30058-2

10 Dowling RJ, Goodwin PJ and Stambolic V: Understanding the benefit of metformin use in cancer treatment. BMC Med 9: 3333, 2011. PMID: 21470407. DOI: 10.1186/1741-7015-9-33

11 Lee TY, Martinez-Outschoorn U, Schilder RJ, Kim CH, Richard SD, Rosenblum NG and Johnson JM: Metformin as a therapeutic target in endometrial cancers. Front Oncol 8: 341, 2018. PMID: 30211120. DOI: 10.3389/fonc.2018.00341

12 Cantrell LA, Zhou C, Mendivil A, Malloy KM, Gehrig PA and Bae-Jump V: Metformin is a potent inhibitor of endometrial cancer cell proliferation-implications for a novel treatment strategy. Gynecol Oncol 116(1): 92-98, 2010. PMID: 19822355. DOI: 10.1016/j.ygyno.2009.09.024

13 Sarfstein R, Friedman Y, Attias-Geva Z, Fishman A, Bruchim I and Werner H: Metformin downregulates the insulin/IGF-I signaling pathway and inhibits different uterine serous carcinoma (USC) cells proliferation and migration in p53dependent or -independent manners. PLoS One 8(4): e61537, 2013. PMID: 23620761. DOI: 10.1371/journal.pone.0061537

14 Tan BK, Adya R, Chen J, Lehnert H, Sant Cassia LJ and Randeva HS: Metformin treatment exerts antiinvasive and antimetastatic effects in human endometrial carcinoma cells. J Clin Endocrinol Metab 96(3): 808-816, 2011. PMID: 21190977. DOI: $10.1210 /$ jc.2010-1803

15 Kim JS, Turbov J, Rosales R, Thaete LG and Rodriguez GC: Combination simvastatin and metformin synergistically inhibits endometrial cancer cell growth. Gynecol Oncol 154(2): 432-440, 2019. PMID: 31178149. DOI: 10.1016/j.ygyno.2019.05.022

16 Chu D, Wu J, Wang K, Zhao M, Wang C, Li L and Guo R: Effect of metformin use on the risk and prognosis of endometrial cancer: a systematic review and meta-analysis. BMC Cancer 18(1): 438-5, 2018. PMID: 29669520. DOI: 10.1186/s12885018-4334-5

17 Pecorelli S: Revised FIGO staging for carcinoma of the vulva, cervix, and endometrium. Int J Gynaecol Obstet 105(2): 103104, 2009. PMID: 19367689. DOI: 10.1016/j.ijgo.2009.02.012

18 Dong L, Zhou Q, Zhang Z, Zhu Y, Duan T and Feng Y: Metformin sensitizes endometrial cancer cells to chemotherapy by repressing glyoxalase I expression. J Obstet Gynaecol Res 38(8): 1077-1085, 2012. PMID: 22540333. DOI: 10.1111/j.14470756.2011.01839.x 
19 Zhang Z, Dong L, Sui L, Yang Y, Liu X, Yu Y, Zhu Y and Feng $Y$ : Metformin reverses progestin resistance in endometrial cancer cells by downregulating GloI expression. Int J Gynecol Cancer 21(2): 213-221, 2011. PMID: 21270604. DOI: 10.1097/IGC. 0b013e318207dac7

20 Sivalingam VN, Kitson S, McVey R, Roberts C, Pemberton P, Gilmour K, Ali S, Renehan AG, Kitchener HC and Crosbie EJ: Measuring the biological effect of presurgical metformin treatment in endometrial cancer. Br J Cancer 114(3): 281-289, 2016. PMID: 26794276. DOI: 10.1038/bjc.2015.453

21 Kitson SJ, Maskell Z, Sivalingam VN, Allen JL, Ali S, Burns S, Gilmour K, Latheef R, Slade RJ, Pemberton PW, Shaw J, Ryder WD, Kitchener HC and Crosbie EJ: PRE-surgical metformin in uterine malignancy (PREMIUM): A Multi-center, randomized double-blind, placebo-controlled phase III trial. Clin Cancer Res 25(8): 2424-2432, 2019. PMID: 30563932. DOI: 10.1158/10780432.CCR-18-3339

22 Davis SR, Robinson PJ, Jane F, White S, Brown KA, Piessens $\mathrm{S}$, Edwards A, McNeilage J, Woinarski J, Chipman M and Bell $\mathrm{RJ}$ : The benefits of adding metformin to tamoxifen to protect the endometrium-A randomized placebo-controlled trial. Clin Endocrinol (Oxf) 89(5): 605-612, 2018. PMID: 30107043. DOI: $10.1111 /$ cen.13830

23 Ezewuiro O, Grushko TA, Kocherginsky M, Habis M, Hurteau JA, Mills KA, Hunn J, Olopade OI, Fleming GF and Romero IL: Association of metformin use with outcomes in advanced endometrial cancer treated with chemotherapy. PLoS One 11(1): e0147145, 2016. PMID: 26788855. DOI: 10.1371/journal. pone. 0147145

24 Ko EM, Walter P, Jackson A, Clark L, Franasiak J, Bolac C, Havrilesky LJ, Secord AA, Moore DT, Gehrig PA and Bae-Jump $\mathrm{V}$ : Metformin is associated with improved survival in endometrial cancer. Gynecol Oncol 132(2): 438-442, 2014. PMID: 24269517. DOI: 10.1016/j.ygyno.2013.11.021

25 Nevadunsky NS, Van Arsdale A, Strickler HD, Moadel A, Kaur G, Frimer M, Conroy E, Goldberg GL and Einstein MH: Metformin use and endometrial cancer survival. Gynecol Oncol 132(1): 236-240, 2014. PMID: 24189334. DOI: 10.1016/ j.ygyno.2013.10.026

26 Hall C, Stone RL, Gehlot A, Zorn KK and Burnett AF: Use of metformin in obese women with type I endometrial cancer is associated with a reduced incidence of cancer recurrence. Int $\mathrm{J}$ Gynecol Cancer 26(2): 313-317, 2016. PMID: 26588235. DOI: 10.1097/IGC.0000000000000603

27 Al Hilli MM, Bakkum-Gamez JN, Mariani A, Cliby WA, Mc Gree ME, Weaver AL, Dowdy SC and Podratz KC: The effect of diabetes and metformin on clinical outcomes is negligible in risk-adjusted endometrial cancer cohorts. Gynecol Oncol 140(2): 270-276, 2016. PMID: 26607780. DOI: 10.1016/j.ygyno. 2015.11.019

28 Seebacher V, Bergmeister B, Grimm C, Koelbl H, Reinthaller A and Polterauer S: The prognostic role of metformin in patients with endometrial cancer: a retrospective study. Eur J Obstet Gynecol Reprod Biol 203: 291-296, 2016. PMID: 27423029. DOI: $10.1016 /$ j.ejogrb.2016.06.013

29 Lemanska A, Zaborowski M, Spaczynski M and NowakMarkwitz E: Do endometrial cancer patients benefit from metformin intake? Ginekol Pol 86(6): 419-423, 2015. PMID: 26255448. DOI: $10.17772 / \mathrm{gp} / 2397$
30 Arima R, Hautakoski A, Marttila M, Arffman M, Sund R, Ilanne-Parikka P, Kangaskokko J, Hinkula M, Puistola U and Läärä E: Cause-specific mortality in endometrioid endometrial cancer patients with type 2 diabetes using metformin or other types of antidiabetic medication. Gynecol Oncol 147(3): 678683, 2017. PMID: 26255448. DOI: $10.17772 / \mathrm{gp} / 2397$

31 Arima R, Marttila M, Hautakoski A, Arffman M, Sund R, Ilanne-Parikka P, Kangaskokko J, Urpilainen E, Laara E, Hinkula $\mathrm{M}$ and Puistola U: Antidiabetic medication, statins and the risk and prognosis of non-endometrioid endometrial cancer in women with type 2 diabetes. Anticancer Res 38(7): 41694178, 2018. PMID: 29970546. DOI: 10.21873/anticanres.12710

32 Arima R, Marttila M, Hautakoski A, Arffman M, Sund R, Ilanne-Parikka P, Kangaskokko J, Laara E, Puistola U and Hinkula M: Antidiabetic medication, statins and the risk of endometrioid endometrial cancer in patients with type 2 diabetes. Gynecol Oncol 146(3): 636-641, 2017. PMID: 28645427. DOI: 10.1016/j.ygyno.2017.06.011

33 Zoungas S, Woodward M, Li Q, Cooper ME, Hamet P, Harrap S, Heller S, Marre M, Patel A, Poulter N, Williams B, Chalmers $\mathrm{J}$ and ADVANCE Collaborative group: Impact of age, age at diagnosis and duration of diabetes on the risk of macrovascular and microvascular complications and death in type 2 diabetes. Diabetologia 57(12): 2465-2474, 2014. PMID: 25226881. DOI: $10.1007 / \mathrm{s} 00125-014-3369-7$

34 Carstensen B, Witte DR and Friis S: Cancer occurrence in Danish diabetic patients: duration and insulin effects. Diabetologia 55(4): 948-958, 2012. PMID: 22120574. DOI: 10.1007/s00125-011-2381-4

35 Bowker SL, Yasui Y, Veugelers P and Johnson JA: Glucoselowering agents and cancer mortality rates in type 2 diabetes: assessing effects of time-varying exposure. Diabetologia 53(8): 1631-1637, 2010. PMID: 20407744. DOI: 10.1007/s00125-010$1750-8$

36 Vigneri R, Goldfine ID and Frittitta L: Insulin, insulin receptors, and cancer. J Endocrinol Invest 39(12): 1365-1376, 2016. PMID: 27368923. DOI: $10.1007 / \mathrm{s} 40618-016-0508-7$

37 Cancer Genome Atlas Research Network, Kandoth C, Schultz N, Cherniack AD, Akbani R, Liu Y, Shen H, Robertson AG, Pashtan I, Shen R, Benz CC, Yau C, Laird PW, Ding L, Zhang W, Mills GB, Kucherlapati R, Mardis ER and Levine DA: Integrated genomic characterization of endometrial carcinoma. Nature 497(7447): 67-73, 2013. PMID: 23636398. DOI: 10.1038 /nature 12113

38 Stelloo E, Nout RA, Osse EM, Jurgenliemk-Schulz IJ, Jobsen JJ, Lutgens LC, van der Steen-Banasik, E. M., Nijman HW, Putter H, Bosse T, Creutzberg CL and Smit VT: Improved risk assessment by integrating molecular and clinicopathological factors in early-stage endometrial cancer-combined analysis of the PORTEC cohorts. Clin Cancer Res 22(16): 4215-4224, 2016. PMID: 27006490. DOI: 10.1158/1078-0432.CCR-15-2878

Received December 2, 2020

Revised January 8, 2021

Accepted January 11, 2021 